\title{
CONTRIBUIÇÕES DA VIVÊNCIA DE CAMPO EM AQUICULTURA PARA EDUCANDOS DE CURSO TÉCNICO DO PROGRAMA NACIONAL DE EDUCAÇÃO NA REFORMA AGRÁRIA
}

\author{
Ivo Thadeu Lira Mendonça (D) , Ugo Lima Silva (D)2, Walter Santos Evangelista \\ Júnior iD3, Luciano Pires de Andrade iD4
}

Resumo: O Programa Nacional de Educação na Reforma Agrária - PRONERA, viabiliza a educação básica e técnica para jovens e adultos inseridos nas políticas do Instituto Nacional de Colonização e Reforma Agrária, promovendo a democratização do conhecimento no campo. Esta pesquisa investigou o aprendizado sobre as condições de utilização dos espaços, os saberes e práticas empregadas e como o cotidiano confronta as experiências de educandos do curso de Técnico em Agropecuária com Ênfase em Agroecologia em Serra Talhada/PE. Para tal, foram utilizadas experiências em campos da aquicultura. Por observação participativa, foram realizadas visitas, caminhada transversal e exposição dialogada sobre as condições de ocupação fundiária, organização social, idealização e capacitação produtiva, manejo técnico, comercialização e dificuldades encontradas pelos produtores. Compartilhando-se as observações, os educandos foram empáticos com os conflitos agrários, que os remetem a mazelas similares. Abordaram temas voltados a organização social, práticas convencionais e agroecológicas encontradas nos tratos culturais. Teceram críticas ao grande aporte de insumos externos necessários para a alimentação dos peixes e os impactos por eles gerados, o que permitiu levantar proposições sobre utilização de insumos locais na adequação de formulações mais eficientes. Perceberam o potencial de replicação das experiências em suas próprias glebas. Avalia-se que a práxis utilizada pelo PRONERA instiga os educandos a pensar sobre a realidade e, sobretudo, a complexidade do mundo rural, tornando-os aptos a julgar criticamente a replicação das práticas e a definir ajustes metodológicos às condições de seus agroecossistemas.

Palavras-chave: Pedagogia de alternância; Educação no campo; PRONERA; Agropecuária; Piscicultura.

\footnotetext{
${ }^{1}$ Doutorando do Programa de Pós-Graduação em Agroecologia e Desenvolvimento Territorial da Universidade Federal Rural de Pernambuco (UFRPE). Extensionista rural do Instituto Agronômico de Pernambuco (IPA). E-mail: ivothadeu@gmail.com.

${ }^{2}$ Doutor em Recursos Pesqueiros e Aquicultura pela Universidade Federal Rural de Pernambuco (UFRPE). Professor Adjunto da Universidade Federal de Rural de Pernambuco (UFRPE). E-mail: ugolimas@gmail.com.

${ }^{3}$ Doutor em Entomologia pela Universidade Federal de Viçosa (UFV). Coordenador do PRONERA/UFRPE. Professor Adjunto da Universidade Federal Rural de Pernambuco (UFRPE). Email: pronera.uast.ufrpe@gmail.com.

${ }^{4}$ Doutor em Etnobiologia e Conservação da Natureza pela Universidade Federal Rural de Pernambuco (UFRPE). Professor Adjunto da Universidade Federal do Agreste de Pernambuco (UFAPE). E-mail: luciano.andrade@ufape.edu.br.
} 


\title{
CONTRIBUTIONS OF FIELD EXPERIENCE IN AQUACULTURE FOR STUDENTS OF TECHNICAL COURSE OF THE NATIONAL PROGRAM FOR EDUCATION IN AGRARIAN REFORM
}

\begin{abstract}
The National Program for Education in Agrarian Reform - PRONERA makes basic and technical education possible for young people and adults inserted in National Institute of Colonization and Agrarian Reform policies, promoting the democratization of knowledge in the countryside. This research investigated the learning about the conditions of use of the spaces, the knowledge and practices employed and how daily life confronts the experiences of students of the Technical Course in Agriculture with Emphasis on Agroecology PRONERA in Serra Talhada/PE. In learning, experiences in aquaculture fields were used. Through participatory observation, were carried out visits, crosssectional walk and dialogue about the local conditions of land occupation, social organization, idealization and productive training, technical management, commercialization and difficulties encountered by fish farmers. When sharing the observations, the students were empathetic with the agrarian conflicts in the region, which lead to similar problems. They approached themes related to social organization, conventional and agroecological practices found in cultural treatments. They criticized the large supply of external inputs needed to feed the fish, and the impacts generated by them, which made it possible to raise proposals on the use of local inputs to adapt formulations that are more efficient. They perceived the potential for replicating experiences in their own fields. The praxis used by PRONERA encourages students to think about the reality and complexity of the rural world, making them able to criticize the replication of practices and to define methodological adjustments to the conditions of their agroecosystems.
\end{abstract}

Keywords: Pedagogy of alternation; Field education; PRONERA; Agriculture; Fish farming.

\section{Introdução}

O Programa Nacional de Educação na Reforma Agrária - PRONERA, criado pela Portaria no 10 de 16 de abril de 1998, propõe e apoia projetos formais de educação básica, técnica e profissional que proporcionem a democratização do conhecimento no campo, voltado especialmente para jovens e adultos inseridos nas políticas do Instituto Nacional de Colonização e Reforma Agrária - INCRA. Por ser uma conquista política dos movimentos sociais e sindicais do campo, 0 PRONERA conserva seu caráter democrático e participativo na estrutura, funcionamento e características das práticas educacionais (FÉLIX, 2015).

O curso prioriza o aprendizado obtido por educandos em uma vivência do curso de Técnico em Agropecuária com ênfase em Agroecologia oferecido pela Universidade Federal de Rural de Pernambuco, Unidade Acadêmica de Serra Talhada - UFRPE/UAST, turma ingressa em 2018, mediante metodologia da pedagogia da alternância, a qual institui um período de educação teórica em 
centro de educação formal e um período em comunidade rural com aplicação prática dos conceitos trabalhados em sala de aula (BRASIL, 2016).

A Pedagogia de Alternância é oriunda do segundo terço do século passado em comunidades rurais europeias que enxergaram a deficiência no atendimento das necessidades educacionais do público rural a partir do modelo tradicional. A partir deste escopo criou-se um modelo atendendo às vicissitudes psicossociais e de profissionalização agropecuária dos educandos a partir de momentos de ensino na escola coordenado por técnico agrícola e momento doméstico, onde os pais acompanhavam as atividades nas glebas, contribuindo com elementos de desenvolvimento social e econômico (TEIXEIRA; BERNARTT; TRINDADE, 2008).

Modelada sob condicionantes de internato, a partir da escolarização teórica intensiva, coparticipação, fazendo-se presentes vários contribuintes e parceiros no processo educacional, e identificação, onde a ação e reflexão dos educandos sejam realizadas no meio social deles, a alternância é uma forma eficiente de aprendizagem agrícola (NOSELLA, 2012). De fato, é uma metodologia instituída em Escolas Família Agrícola - EFA's, e pelas Casas Familiares Rurais - CFR's, amplamente distribuídas por todas as regiões do território nacional (TEIXEIRA; BERNARTT; TRINDADE, 2008).

A Pedagogia da Alternância corrobora com a compreensão do espaço e o que se aplica também ao semiárido nordestino. Com sua instrumentalização observa-se mudanças qualitativas na participação de jovens assentados quanto ao seu entendimento, análise e intervenção da realidade da qual fazem parte atribuindo-Ihes ferramentas para alçar novas práticas estruturadas em conceitos congruentes ao aproveitamento ecológico do agrossistema (MELO; MIYATA, 2009).

Alicerçado em módulos disciplinares condensados, o curso Técnico em Agropecuária com ênfase em Agroecologia da UFRPE/UAST estrutura-se, conforme o manual orientador, em processos educativos em diferentes tempos e espaços, transversalidade dos conhecimentos do campo, formação profissional para além dos espaços escolares, rearticulação da relação teoria-prática e aproximação com o desenvolvimento sustentável do campo (BRASIL, 2016).

Identifica-se no público esperado deste curso características diversas a partir de etnia, gênero, orientação, classe, geração, credo, experiências vividas, região domiciliar, entre outros, onde cada integrante carrega tradições de autonomia produtiva e manifestações culturais próprias que dirigem, ontologicamente seu modo reprodução (WANDERLEY, 2003). Tal percepção é inerente ao público alvo do PRONERA, sendo população jovem e adulta das famílias beneficiárias dos projetos de assentamento criados ou reconhecidos pelo INCRA e do Programa Nacional de Crédito Fundiário - PNFC, assentadas, acampados, remanescentes quilombolas e extrativistas, assim como participantes de ações e programas coordenados pelo INCRA e identificadas em normativas próprias, como beneficiários do Plano Nacional de Reforma Agrária - PNRA (BRASIL, 2016), conferindo um cenário plural da reprodução camponesa.

A partir da proposta orientadora, organizou-se a ementa e metodologia de ensino do programa aplicados a conceitos e práticas da aquicultura, seguimos 
com a explanação e caracterização da exploração aquícola de base familiar no município de Petrolândia/PE. Em seguida foram elencadas as experiências e discussões procedidas fruto das vivências realizadas pelo módulo acadêmico e finalizou-se com comentários sobre as habilidades e competências expostas pelos educandos advindas da capacitação em questão.

Investigou-se como os egressos do PRONERA interagem os saberes adquiridos no módulo de aquicultura dentro do curso de Técnico em Agropecuária com Ênfase em Agroecologia com o espaço de origem, onde é esperado que os educandos possam visualizar as condições de utilização dos espaços, os saberes aplicados, as práticas empregadas e como o cotidiano apresentado confronta com suas experiências adquiridas nos espaços de formação. Procurou-se verificar se os educandos conseguem admitir e aplicar as competências previstas pela proposta pedagógica, a partir das práxis da Pedagogia de Alternância, possibilitando a replicação das experiências em suas glebas rurais.

\section{Metodologia}

A turma de 34 educandos participantes que compôs o curso Técnico em Agropecuária com ênfase em Agroecologia foi coerente com o perfil de público em que se objetiva o PRONERA (Quadro 1).

\section{Quadro 1 - Perfil dos educandos do Curso Técnico em Agropecuária com ênfase em Agroecologia do PRONERA/UFRPE-UAST.}

\begin{tabular}{|lccc|}
\hline \multicolumn{1}{|c}{ Beneficiário PRONERA } & $\begin{array}{c}\text { Número de } \\
\text { educandos }\end{array}$ & Gênero & Município abrangidos \\
\hline $\begin{array}{l}\text { Movimento dos Trabalhadores } \\
\text { Rurais Sem Terra (MST) }\end{array}$ & 04 & Feminino & $\begin{array}{c}\text { Betânia, Caruaru, Goiana, Iati, } \\
\text { Ibimirim, Inajá, Manari, Mirandiba, } \\
\text { Orocó, Passira, Petrolândia, São } \\
\text { José do Belmonte, Serra Talhada, } \\
\text { Tupanatinga }\end{array}$ \\
\hline $\begin{array}{l}\text { Povos tradicionais } \\
\text { (Quilombolas) }\end{array}$ & 05 & Feminino & Mirandiba \\
\hline $\begin{array}{l}\text { Comissão Pastoral da Terra } \\
\text { (CPT) }\end{array}$ & 04 & Masculino & Feminino \\
\hline TOTAL & 02 & Masculino & São José do Egito, Iguaraci \\
\hline
\end{tabular}

Fonte: Elaborado pelos autores.

O percurso pedagógico definido pelo plano de aulas no âmbito do PRONERA utilizado no transcorrer da disciplina de Aquicultura cursada em 11 módulos, em fevereiro de 2020 , delineou a reprodução da prática mediante a aplicação de conceitos teóricos pertinentes à aquicultura (Quadro 2), a qual teve como ementa: a aquicultura no Brasil e no mundo; importância da aquicultura como alternativa para segurança alimentar; definição de princípios, técnicas e conceitos básicos envolvendo características de espécies cultiváveis; sistemas de cultivo, instalações aquícolas, seleção de áreas, otimização do uso da água, manejo de cultivo, requerimentos ambientais e nutricionais, sistema de 
recirculação, policultivos; concepção e planejamento de projetos aquícolas sustentáveis.

\section{Quadro 2 - Descrição das atividades, por módulo, desenvolvidas na disciplina Aquicultura no curso Técnico em Agropecuária com ênfase em Agroecologia do PRONERA/UFRPE-UAST.}

\begin{tabular}{|c|c|}
\hline Módulo & Local e atividades desenvolvidas \\
\hline $\begin{array}{l}1 \\
2 \\
3\end{array}$ & $\begin{array}{l}\text { Módulos ocorridos na sede na UFRPE em Recife/PE, organizamos uma abordagem teórica } \\
\text { e conceitual da atividade, com aulas expositivas, vídeo aulas, dinâmicas de grupos e } \\
\text { problematizações sobre: o que é aquicultura, cultivo de organismos aquáticos, conceito } \\
\text { geral da piscicultura no Brasil e no mundo, espécies cultiváveis (nativas e exóticas), } \\
\text { cultivos (modos de produção) intensivo, semi-intensivo e extensivo, fases da criação de } \\
\text { tilápia e camarão, critérios para seleção de área na aquicultura. }\end{array}$ \\
\hline 4 & $\begin{array}{l}\text { Visita técnica a um carcinicultura familiar no município de Feira Nova/PE produtora de } \\
\text { camarão de água marinho Litopennaeus vannamei em águas de baixa salinidade, quando } \\
\text { foi possível realizar práticas de manejo produtivo como biometria, cálculo de ração, } \\
\text { análise de salinidade com refratômetro, construção de viveiro, fertilização e despesca, } \\
\text { apresentando as condições necessárias para o desempenho produtivo. }\end{array}$ \\
\hline 5 & $\begin{array}{l}\text { ódulo realizado no In } \\
\text { blioteca agropecuária } \\
\text { aplder Câmara e sister } \\
\text { aproximação de parce }\end{array}$ \\
\hline 6 & $\begin{array}{l}\text { Visita técnica a Estação de Aq } \\
\text { UFRPE, Recife/PE, contribuindo p } \\
\text { cultiváveis e ambientes de cultiv }\end{array}$ \\
\hline 7 & $\begin{array}{l}\text { Módulo realizado na Base de Piscicultura Ornamental e Pesquisa Marinha - POPMAR, } \\
\text { Campi Avançado da UFRPE, localizado no município de Ilha de Itamaracá/PE, com } \\
\text { palestra sobre peixes ornamentais, aquarismo e piscicultura ornamental a fim de elencar } \\
\text { a pluralidade de ações na atividade. }\end{array}$ \\
\hline 8 & $\begin{array}{l}\text { zado na Estação de Agricultura Irrigada de Ibimirim/PE UAST/UFRPE, onde tratamos } \\
\text { ranicultura e qualidade da água para aquicultura, quando os educandos puderam } \\
\text { ar análise das variáveis físicas e químicas de qualidade da água de açudes poço da } \\
\text { Ibimirim/PE e poços artesianos à fomentar a compreensão da interferência do meio } \\
\text { ente sobre o espaço de cultivo. }\end{array}$ \\
\hline 9 & $\begin{array}{l}\text { Encontro realizado no Serviço de Tecnologia Alternativa - SERTA, em Ibimirim/PE, com } \\
\text { visita a sistema de aquaponia agrovoltáica sustentável, que é criação conjunta de peixes } \\
\text { e hortaliças, com vistas em análise de qualidade de água estimulando a inter-relação } \\
\text { possível entre várias culturas. }\end{array}$ \\
\hline 10 & $\begin{array}{l}\text { Visita a duas experiências de produção de pescados desenvolvidas por piscicultores } \\
\text { familiares na zona rural de Petrolândia/PE: uma unidade cooperativista de produção } \\
\text { intensiva de tilápia Oreochromis niloticus desenvolvida em tanques-rede e uma gleba } \\
\text { agropecuária com a presença de várias culturas consorciadas ao policultivo de panga } \\
\text { Pangasius hypophthalmus com camarão de água doce Macrobrachium rosenbergii em } \\
\text { viveiros escavados, de modo a observar diferentes modelos comercialmente produtivos. }\end{array}$ \\
\hline 11 & $\begin{array}{l}\text { Módulo final realizado na sede na UFRPE em Recife/PE, quando ocorreu o fechamento da } \\
\text { disciplina/módulo de aquicultura com apresentação e discussão geral de relatórios das } \\
\text { vivências apresentados pelos educandos. }\end{array}$ \\
\hline
\end{tabular}

Fonte: Elaborado pelos autores.

As atividades estruturaram-se em momentos teórico-práticos a fim de situar e problematizar fatos vivenciados no cotidiano da atividade aquícola e fomentar a integração bem como a troca de saberes de forma participativa (Figura 1), principalmente, entre produtores familiares, seguindo preceitos metodológicos de observação participante. 


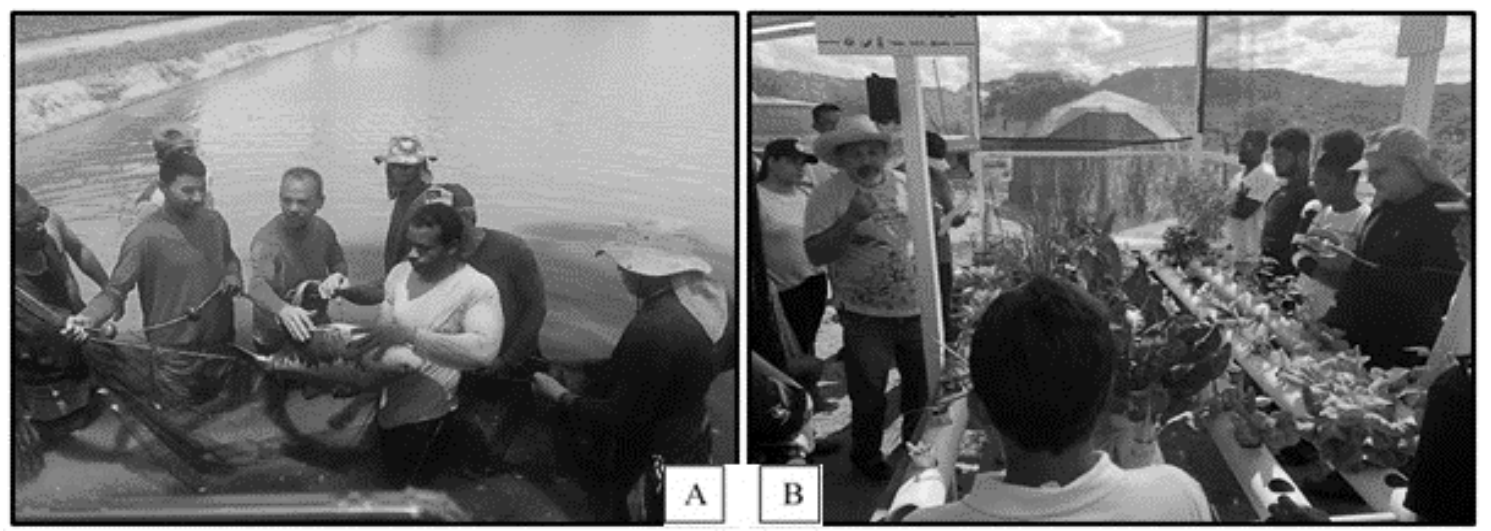

Figura 1: Excursão de educandos do curso de Técnico em Agropecuária com ênfase em Agroecologia da UFRPE/UAST a unidades de aquicultura em: (A) piscicultura em viveiros escavados na Estação de Aquicultura do Departamento de Pesca e Aquicultura da UFRPE, Recife/PE, e (B) sistema de aquaponia agrovoltaica sustentável no Serviço de Tecnologia Alternativa - SERTA, Ibimirim/PE.

Fonte: Acervo próprio.

Através da observação, os investigadores descreveram e categorizaram dos dados coletados durante as vivências teórico-práticas, onde os raciocínios críticos partidos dos educandos sobre temas de conflitos fundiários, uso de insumos externos, organização socioeconômica, exploração do agrossistema, comercialização do pescado e estrutura da cadeia produtiva foram tidas como variáveis qualitativas. Os dados coletados eram relatados em diário de campo para posterior sistematização e análise.

Em especial, a vivência teórico-prática do $10^{\circ}$ módulo sobre produção de pescados por piscicultores familiares em Petrolândia/PE foi assistida pelo Instituto Agronômico de Pernambuco - IPA, onde utilizou-se as ferramentas metodológicas de extensão de exposição dialogada e caminhada transversal (PEREIRA et al., 2009). Foram abordadas as condições locais de ocupação fundiária, organização social, idealização da exploração, capacitação produtiva, manejo técnico, comercialização e dificuldades encontradas pelos produtores no intuito de apresentar o cotidiano dos piscicultores e subsidiar o entendimento e a sistematização do espaço pelos educandos.

No módulo final realizado na sede na UFRPE em Recife/PE foi desenvolvido o fechamento da disciplina de Aquicultura, onde realizaram-se apresentações e discussão geral de trios de educandos a partir de relatórios descritivos redigidos a partir dos módulos vivenciados.

\section{Resultados e discussões}

Silva, Lima e Feitosa (2020) relataram suas experiências como educandos em relatório de vivência em campo apresentado e compartilhado com a turma no último módulo da disciplina, como segue:

O módulo de Aquicultura foi muito proveitoso onde adquirimos conhecimentos específicos de cada área da piscicultura, carcinicultura e ranicultura, com suas fases reprodutivas, fisiológicas, produtivas, vantagens e desvantagem, desde pequenos a grandes projetos, adquirimos o conhecimento e vimos a necessidade de se fazer uma 
análise de solo e água para assim ter um equilíbrio ambiental. A aquicultura nos proporcionou a consciência de que através dela podemos adquirir uma boa renda familiar através da criação de peixe, camarão e rãs também podendo assimilar a aquicultura com a agricultura (SILVA; LIMA; FEITOSA, 2020, p. 15).

Cursadas todas as experiências práticas de campo, é dado luz à excursão realizada à zona rural de Petrolândia/PE do $10^{\circ}$ módulo, vivenciando as práticas e desafios desenvolvidos por piscicultores familiares.

\subsection{O arranjo produtivo da aquicultura em Petrolândia/PE}

O município de Petrolândia está inserido na depressão semiárida de Pernambuco numa mesorregião chamada de Itaparica e que é margeado pelo lago artificial de mesmo nome formado pelo barramento do Rio São Francisco através da Usina Hidrelétrica de Luiz Gonzaga. Mesmo com população predominantemente urbana, possui como base econômica o setor de serviços e a agropecuária, principalmente, por hortifruticultura irrigada, caprinovinocultura e piscicultura, em que a segunda ocupa cerca de $37 \%$ do pessoal e gera um rendimento médio per capita mensal acima de $1 / 2$ salário-mínimo (CONDEPE/FIDEM, 2020).

Uma situação capital que influiu diretamente na reprodução socioeconômica do município foi a relocação compulsória do público que ocupava terras que foram submersas pelo lago, movimento este convencionado de Projeto Reassentamento Itaparica. Os agricultores atingidos que perderam suas glebas em áreas ribeirinhas foram realojados em lotes familiares dentro de Perímetros Irrigados Públicos distribuídos ao longo da região (SCOTT, 2009).

Os agricultores atingidos tinham base campesina com atividades agropecuárias voltadas ao abastecimento local, com culturas da cesta básica de consumo como feijão, arroz, milho, hortaliças, raízes e tubérculos e criação de pequenos animais em áreas de várzea aproveitando o solo enriquecido pela ação das cheias naturais (CODEVASF, 2019). Havia ainda estrutura de comércio e serviços direcionados a suprir as necessidades e demandas exigidas para a atividade agropecuária (MENEZES; MARQUES; NOVAES, 2017).

A íntima ligação que os camponeses mantinham com o meio assentavase no movimento cíclico das águas que era responsável pela delimitação de áreas de plantio, determinação das formas e procedimentos de trabalho, seleção das culturas a serem exploradas e moderação do rebanho a ser trabalhado definindo um padrão de identidade ambiental (MENEZES; MARQUES; NOVAES, 2017).

A estrutura utilizada era relativamente rudimentar, utilizando tecnologias agropecuárias precárias com pouco ou nenhum aparato mecanizado, porém eficientemente adaptados a reprodução local e a comercialização consistia na troca de produtos, onde forneciam seus excedentes produtivos adquirindo aqueles que não produziam (CODEVASF, 2020). Contudo, as perspectivas de entidades interessadas no processo de evacuação da área podem estar condicionadas a apresentar um aspecto de estagnação, desarticulação e desuso do espaço a ser apropriado, num enfoque de desvalorização de critérios 
indenizatórios ou facilitação em condicionantes para realocação, sob circunstâncias de conflitos de interesse.

Após a submersão os atingidos foram direcionados para os Perímetros Irrigados Públicos. Em número de nove, estas estruturas foram implantadas em áreas distantes dos territórios identitários dos camponeses. O processo transcorreu com o cadastramento dos beneficiários distribuindo-se lotes padronizados entre 1,5 e 6,0 hectares, definidos pelo número de integrantes das famílias, equipados com sistema de irrigação convencional em solos predominantemente arenosos ou com ocorrências de aflorações rochosas e alagadiços, os quais eram classificados como lotes descartados (SCOTT, 2009).

Sucedeu-se que os reassentados tentavam reproduzir seus conhecimentos tradicionais de agricultura de vazante em seus lotes sem alcançar resultados esperados. Ao contrário, a falta de conhecimento específico junto a sobre-exploração de uma mesma parcela sem possibilidade de descanso ou rotação do solo minimizavam sua capacidade produtiva (LIMA, 2007).

Foram identificadas situações de desconforto psicossocial nos reassentados, uma vez que a comunidade original, que possuía reprodução de troca e colaboração produtiva e vínculo com o território, foi desfeita pela relocação em vilas dimensionadas que não comportavam toda a comunidade rasgando os laços culturais ali presentes e forçando a desconstrução da estrutura socioeconômica local (MENEZES; MARQUES; NOVAES, 2017). Cernea (2004) ratifica estas alegações como inerentes ao impacto social causado por ações de reassentamento de populações.

As situações encontradas desencadearam a mazela da falta de sustentabilidade dos lotes irrigados, principalmente pela restrição produtiva ocasionada pela limitação de área disponível com necessidade de utilização de tecnologia agrícola até então desconhecida pelos reassentados e pela desarticulação sobre a distribuição dos excedentes produtivos devido a decomposição comercial da sociedade (LIMA, 2007).

Como uma tentativa de mitigação dos impactos de natureza, produtiva, econômica e social dos atingidos foram instituídos programas públicos de acompanhamento técnico e social. Entretanto a descontinuidade e princípios norteadores alinhados a critérios tecnicistas e mecanizados surtiram pouco efeito com o público-alvo (LIMA, 2007).

Galvão (1999) aponta que as glebas distribuídas no início do reassentamento já tinham proporções físicas insuficientes para abastecer as famílias e comunidade, o que foi exponencialmente acrescido com o aumento populacional advindo do crescimento e multiplicação familiar.

A aglomeração de contingente num espaço limitado, o crescimento do número de pessoas nas famílias, a limitação produtiva das cultivares, bem como o esgotamento do solo por sucessivos plantios na mesma área e a salinização das camadas superficiais por excesso hídrico ou adubar, se transformaram em um problema de socioeconômico e ambiental de proporções incalculável, uma vez que fundamentalmente, os assentados provinham de áreas de exigiam tratos culturais próprios, diferentes aos aplicados nas glebas. Tal situação forçou uma busca por agroecossistema produtivos passíveis de exploração consciente como uma saída visando a subsistência da comunidade e ocupação de fatias 
populacionais subaproveitadas como o caso dos jovens que almejavam sua emancipação.

Sob um novo contexto de Assistência Técnica e Extensão Rural - ATER, utilizando orientações descentralizadas, contextualizadas e participativas, entidades como a Diocese de Floresta, Prefeitura Municipal de Petrolândia, Instituto Agronômico de Pernambuco - IPA, Programa Estadual de Apoio ao Pequeno Produtor Rural - Prorural, e Banco do Brasil somaram esforços em proporcionar uma nova fronteira de exploração sustentável que incorporasse a reprodução da região, de maneira integrada com ações planejadas e distribuídas a partir de suas competências, evitando descontinuidade e sobreposição de esforços (ROCHA; VITAL, 2012).

Uma das tecnologias apresentadas foi a aquicultura, que é baseada no cultivo racional de organismos aquáticos a partir de ação antrópica, exercendo controle sobre a alimentação, crescimento e reprodução, visando retorno quer seja de subsistência ou econômico (KUBITZA, 2000). Nessa perspectiva, os atores foram capacitados, regularizados e equipados com apetrechos produtivos necessários ao início da produção e alocados em pequenas áreas com acesso a margem do lago. Os atores que voluntariamente se manifestaram interessados eram reassentados socialmente vulneráveis e subaproveitados em suas glebas, aptos a uma alternativa produtiva viável, justa, coerente, compatível com seu tempo disponível e que preservava sua atividade principal.

A concepção da aquicultura foi centrada em pequenos produtores de base familiar associados e aglomerados num mesmo espaço de produção, entendidos como condomínios produtivos, onde concentram o esforço de cultivo e desenvolvem o autoemprego. Estes condomínios respondem hoje por mais de $80 \%$ das unidades atualmente presentes na região (IBGE, 2019). São regidos pelo princípio de economia solidária, preconizados por democratização econômica, trabalho colaborativo e autogestionário, onde agregam volume produtivo, buscando igualdade de oportunidades frente a grandes produtores da região, bem como a garantia de direitos fundamentais e preservação do meio (SILVA; NAGEM, 2012).

A exploração típica desenvolvida em Itaparica foi a piscicultura com o cultivo da tilápia Oreochromis niloticus, espécie exótica, porém presente na bacia do rio São Francisco, em gaiolas flutuantes alocadas na superfície do lago chamadas de tanques-rede. Este modelo de produção intensiva, adensando grandes quantidades de peixes em pequenos espaços, exige a necessidade de controle contínuo e absoluto sob tutela de pessoal capacitado, devido a permissividade de utilização de pequenos espaços físicos em detrimento ao aproveitamento socioeconômico em meio ao espelho d'água (BARROSO et al., 2018).

Outra atividade desenvolvida, sob exploração semi-intensiva, foi a instalação de viveiros escavados em solo natural, utilizando áreas esgotadas ou inaptas para a agricultura, cultivando pescados de diferentes espécies, em que no caso visitado utilizava-se o panga Pangasius hypophthalmus junto ao camarão de água doce Macrobrachium rosenbergii ocupando o mesmo ambiente, tomado como policultivo. Essa forma de exploração foi adotada como complementar a lavoura agrícola da gleba, fazendo uso econômico do espaço 
improdutivo, fomentando o uso de água verde para fertirrigação, pela concentração de nutrientes como nitrogênio e fósforo oriunda da aquicultura, dispensando a necessidade de aporte de adubos externos na lavoura (FARIA et al., 2013).

Os manejos utilizados nos diferentes sistemas empregados nos condomínios caracterizam-se pela mão de obra própria e colaborativa, onde associam seus meios de produção, redistribuindo insumos presentes de pouca ou nenhuma mecanização e congruente com a capacidade suporte do ambiente, priorizando assim princípios agroecológicos no modelo de exploração, mesmo em espaços confinados.

O regime solidário incentivou a fusão dos esforços numa cooperativa agropecuária, Cooperativa Agroaquicola de Petrolândia - CAAP, cuja função é centrada no apoio produtivo aos seus cooperados de forma a adquirir insumos, planejar a produção, comercializar e distribuir seus produtos da melhor maneira possível, proporcionando melhores condições de mercado, maior abrangência e curtos estratos de comércio. Instituiu-se também um fórum de produtores de forma a unificar propostas e práticas de produção, estruturação da cadeia e relacionamento com entes federativos, propiciando a integridade e longevidade do ambiente produtivo.

Estas configurações foram formadas e consubstanciadas por permitir o compartilhamento dos meios de produção, assegurar a autonomia e soberania dos piscicultores e incentivar as práticas de produzir e consumir dentro da comunidade (CABALLERO et al., 2010).

A grande dificuldade da atividade praticada está situada na falta de estrutura para etapa final da cadeia produtiva, devido ao sistema legal definir critérios próprios para a comercialização e distribuição de produtos de origem animal, tal qual o serviço de inspeção animal. Isto porque a implantação e manutenção das instalações necessárias para o atendimento dos normativos legais aplicáveis ao serviço de inspeção, como estrutura física de beneficiamento de pescado e procedimentos tarifários, são restritas a grandes produtores que conseguem arcar com os custos e serviços especializados exigidos pelos processos.

Os pequenos produtores acabam assim condicionados à informalidade, sujeitos a sanções legais e marcados como fornecedores de produtos de baixa qualidade sanitária. A realidade é combatida no fórum comunitário a fim de agregar esforços dos produtores e entres públicos propiciando a instalação do serviço de inspeção na região, instituindo a legalidade do produto comercializado.

\subsection{Mais um dia no campo: a descoberta de outros cotidianos}

Após a aplicação das ferramentas metodológicas de extensão foi aberto um espaço de coletivo de discussão onde foram compartilhadas as observações dos educandos sobre a experiência apresentada, sendo, em muitos casos, o primeiro contato com a atividade desenvolvida sob estas formas de sistemas produtivos (Figura 2). 

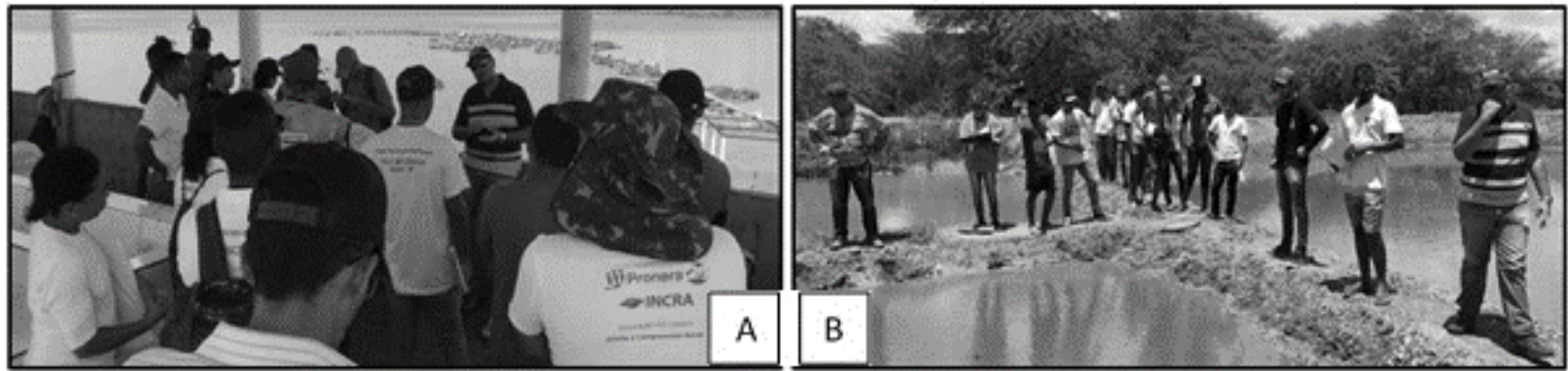

Figura 2: Excursão de educandos do curso de Técnico em Agropecuária com ênfase em Agroecologia da UFRPE/UAST a unidades de aquicultura em Petrolândia/PE: (A) piscicultura em tanques-rede; e (B) policultivo em viveiros escavados.

Fonte: Acervo próprio.

Comentários e críticas surgiram em diversos temas, contudo se concentraram na organização social e práticas convencionais e agroecológicas encontradas nos processos, devido ao intuito do curso basear-se na reprodução e replicação de marcos agroecológicos em agroecossistemas produtivos (Quadro 3).

Os educandos assimilaram os fatos cotidianos das experiências vividas e foram empáticos com a realidade fundiária encontrada no Sistema Itaparica uma vez que conflitos agrários, expulsão territorial, disputas por espaço produtivo, mesmo quando discrepantes, remetem a mazelas similares, o que é comum a uma ampla gama da população campesina (CRUZ, 2014).

Para Peres (2017), conflitos agrários, principalmente em regiões sertanejas, são concebidos de estruturas institucionais oligárquicas, provenientes do coronelismo, que incitam, ao longo do tempo a reprodução de violência, corrupção, clientelismo, favorecimentos e subjugação.

\section{Quadro 3 - Observações relatadas em visita técnica por educandos da disciplina de Aquicultura do curso Técnico em Agropecuária com ênfase em Agroecologia do PRONERA/UFRPE-UAST.}

\begin{tabular}{|c|l|}
\hline Temática discutida & \multicolumn{1}{|c|}{ Observações dos educandos } \\
\hline $\begin{array}{c}\text { Conflitos } \\
\text { fundiários }\end{array}$ & $\begin{array}{l}\text { Foram empáticos por ser uma situação comum a uma ampla gama da } \\
\text { população campesina. }\end{array}$ \\
\hline $\begin{array}{c}\text { Uso de insumos } \\
\text { externos }\end{array}$ & $\begin{array}{l}\text { Criticaram o grande aporte de nutrientes no meio e os seus impactos } \\
\text { gerados; } \\
\text { Repreenderam o consumo de alimento à base de cultivares transgênicas } \\
\text { pelos peixes; } \\
\text { Propuseram a utilização de insumos locais adequando a formulações e } \\
\text { manufatura eficientes à produção. }\end{array}$ \\
\hline $\begin{array}{c}\text { Organização } \\
\text { socioeconômica }\end{array}$ & $\begin{array}{l}\text { Enalteceram as condições de economia solidária dos produtores pautadas } \\
\text { pela reciprocidade e redistribuição. }\end{array}$ \\
\hline $\begin{array}{c}\text { Exploração do } \\
\text { agrossistema }\end{array}$ & $\begin{array}{l}\text { Censuraram a utilização do modelo em monocultura da piscicultura em } \\
\text { tanques-rede; } \\
\text { Valorizaram o uso racional da água nos viveiros propiciando a fertirrigação } \\
\text { dos plantios e a diversificação das lavouras. }\end{array}$ \\
\hline $\begin{array}{c}\text { Comercialização } \\
\text { do pescado }\end{array}$ & $\begin{array}{l}\text { Elogiaram a estratégia coletiva sob modelos de proximidade e curtos } \\
\text { estratos de comercialização organizados em cooperativa agropecuária. }\end{array}$ \\
\hline $\begin{array}{c}\text { Estrutura da } \\
\text { cadeia produtiva }\end{array}$ & $\begin{array}{l}\text { Lamentaram a ausência de condições para participação em mercados } \\
\text { varejistas formais e programas governamentais de aquisição de alimentos; }\end{array}$ \\
\hline
\end{tabular}


Repreenderam a complexidade para a instalação do beneficiamento do pescado para o pequeno produtor.

Fonte: Elaborado pelos autores.

E no caso de inundações por barragens, a premissa se faz verdadeira, uma vez que só após o projeto de barramento estar concebido e contratado por grandes empreiteiras, se inicia o processo de avaliação de impactos sociais. E a partir de medidas ditas neutralizadoras, procuram mitigar as eventuais consequências causadas às populações locais, para as quais não existem soluções democráticas possíveis (SIGAUD, 1994; FEARNSIDE, 2017) devido as constantes lacunas postas por inesperados impactos socioambientais indiretos ou cumulativos (HESS; FENRICH, 2017), mesmo qualificando os serviços básicos a serem oferecidos aos atingidos (RANDELL, 2016).

A necessidade de grande volume de insumos externos necessários para a alimentação dos peixes na forma de ração peletizada extrusada, provenientes de grandes indústrias e com matéria prima oriunda de cultivares transgênicas, geram críticas em virtude do grande aporte de nutrientes no meio e os seus impactos gerados, inclusive sobre possíveis reflexos no pescado produzido pelo consumo de alimento à base de cultivares transgênicas. Deve-se a adoção do conceito em que a transgenia de organismos se baseia em beneficiar o agronegócio das grandes safras e do mercado econômico em detrimento a qualidade dos alimentos, estando passíveis a riscos de saúde pública e ambiental poucos evidenciados, devido aos altos custos da biotecnologia serem realizados pelas próprias empresas geradoras das patentes (LOPES, 2017). Nobre et al. (2020) apontam que ao menos 50\% dos grãos e farinhas consumidos em região do semiárido são transgênicos e chamam atenção a possibilidade de que esses produtos podem viabilizar diversas enfermidades.

Os educandos levantaram indagações e proposições sobre a utilização de insumos locais adequando a formulações e manufatura eficientes à produção. É sabido que o correto manejo alimentar é fator imprescindível ao bom desempenho de cultivos pecuários, onde para tal é necessário ofertar um alimento que atenda a demanda nutricional dos animais. $E$, por conseguinte, na possibilidade de formulação de rações balanceadas com ingredientes ditos alternativos presentes na região e mais condizentes a critérios ambientais como o sorgo, algaroba, leucena, ou mandioca, quer sejam como fontes energéticas ou proteicas, em detrimento a componentes tradicionais muitas vezes transgênicos, como soja, milho e trigo, embora seja necessário o emprego de tecnologia e manufatura adequada (SANTOS et al., 2008; PEZZATO; BARROS; FURUYA, 2009).

As condições de economia solidária dos produtores no manejo, quando presenciaram a contribuição coletiva na mão de obra necessária ao cultivo pautada pela cooperação entre os participantes, instaurando um conglomerado produtivo e rateando igualitariamente as despesas geradas foi um dos pontos de maior destaque por parte dos discentes.

Estratégias de organizações condominiais rurais são implementadas sobre o vislumbre de soma dos recursos disponíveis trabalhados em sinergismo a fim de obter melhores resultados de que se agissem de forma isolada, além de cumprir papéis complementares de incentivo a características de gênero e 
geração corroborando com a reprodução da tríade família, produção e trabalho (KIYOTA; PERONDI; VIEIRA, 2012).

Silva e Nagem (2012) explicam o caráter positivo do arranjo coletivo pela otimização de fatores produtivos quer sejam humanos ou materiais, exacerbando a viabilidade, regularidade e competitividade da atividade, bem como da qualidade psicossocial dos associados, através da majoração da renda, combate a desocupação e marginalização, elevação de autoestima e fomento ao engajamento comunitário e político.

Contudo, os educandos avaliaram negativamente a inexistência de culturas suplementares que pudessem contribuir com os princípios agroecológicos, mesmo nos pequenos espaços destinados a produção, no caso das instalações de tanque-rede que estão pautadas numa monocultura, passível de interpretações à modelos empresariais. Essa preocupação nasce do processo de modernização agrícola da revolução verde, ou do desenvolvimento rural no caso diferenciado da região Nordeste, incorporando padrões industriais, comerciais, financeiros hábitos urbanos, que incentivou a exclusão, proletarização e pauperização da população do campo (NAVARRO, 2001).

Entende-se o fato criticado uma vez que, por geralmente, são vistos em outras localidades, inclusive no semiárido, onde o princípio de desenvolvimento rural moldado pelo modelo eurocêntrico incentiva a dinâmica capitalista com concentração fundiária, enterrando os meios de produção da comunidade local (SIGAUD, 1994; ALBANO; SÁ, 2009).

Todavia, o presente arranjo tenta instituir-se num modelo familiar díspar deste, tal qual a interação com a pesca extrativa, partindo da aglomeração de peixes nativos nas proximidades das baterias de cultivo, beneficiando pescadores locais, ou o próprio desempenho de outras culturas pelos associados em suas glebas de origem utilizando resíduos e subprodutos do pescado como insumos.

No caso dos viveiros escavados, valorizaram a forma de uso racional da água necessária à irrigação dos plantios, tão valiosa para as condições do semiárido, além da estratégia na adubação, onde observaram a racionalização dos recursos disponíveis somado a diminuição de custos na lavoura e a possibilidade de expandir o leque de produtos gerados na gleba fomentando a seguridade alimentar. A técnica de fertirrigação de lavouras com efluentes de piscicultura se mostra como uma excelente solução para culturas agroecológicas, uma vez que contribui com a ciclagem e disponibilização de nutrientes, otimizando a mineralização da matéria orgânica, elevando a qualidade do solo, bem como sua combinação com compostos orgânicos mostram-se substitutos viáveis a adubação inorgânica (SILVA, 2019).

Em relação a segurança alimentar, o pescado é um alimento que se destaca quanto à quantidade e qualidade das suas proteínas. No Nordeste brasileiro ele é bem aproveitado, tendo consumo mais elevado que a média nacional impulsionado pela disponibilidade gerada pelas políticas de incentivo o peixamento e produção, porém com amplo espaço a expansão da atividade, se comparado a crescente demanda pelo produto (SARTORI; AMANCIO, 2012).

Reconheceram a estratégia exitosa da comercialização do pescado realizado de forma coletiva sob modelos de proximidade e curtos estratos de 
comercialização, através de cooperativa agropecuária, que possibilita a distribuição do produto por valores acessíveis diretamente aos consumidores da comunidade e município, embora sejam submetidos a atravessadores para atingir a região. Perspectivas em torno de vínculos sociais nas relações comerciais adquirem uma forma de valoração própria, onde estão presentes parcelas contributivas econômica e socialmente alternativas ao posto por modelos desenvolvimentistas, conferindo propostas aprazíveis a ambas as partes envolvidas, como também a oportunidade de criar articulações que minimizem fragilidades em meio ao mercado (GONÇALVES, 2008; GARCIA, 2014).

Também se mostraram compadecidos pela ausência de estrutura da cadeia produtiva do pescado e carnes para participação nos mercados varejistas formais e em programas governamentais de aquisição de alimentos, uma vez que os produtores já integraram os programas cedendo pescado e outros de seus produtos, e que os levou a cessar o fornecimento. Indagaram sobre as condicionantes para implantação de tais estruturas, surpreendendo-se com os custos e variantes necessárias para funcionamento. A cadeia do pescado é uma complexa estrutura dotada de diversas variantes e segmentos de negócio e encontra no beneficiamento do produto o seu principal gargalo, exigindo distintas expertises que muitas vezes exigem conhecimentos avançados em gerenciamento, tratamento e regulação industrial, além da possibilidade de geração de rejeitos impactantes ao meio promovendo uma atmosfera que rechaça a presença do pequeno produtor, muito embora haja o esforço do poder público a aproximar o aquicultor familiar de programas de estruturação física e aquisição de alimentos (GUIMARÃES; VENDRAMINI, 2015).

\section{Considerações finais}

O contato com uma ampla gama de estratégias produtivas, competências e mecanismos de aproveitamento do espaço rural demonstram o potencial da atividade na área investigada. Por sua vez a práxis educacional da Pedagogia de Alternância torna-se uma ferramenta diferencial na construção do conhecimento, pois facilita a transformação de discussões teóricas realizadas no ambiente formal em apontamentos práticos no ambiente produtivo.

A possibilidade de replicação com leitura crítica de experiências exitosas em seus territórios (glebas e comunidade) através de princípios que contribuem com marcos agroecológicos como reciprocidade e biodiversidade, salvo a modelos tidos como incoerentes por seus conhecimentos, refutados pela proximidade a práticas associadas a conceitos do agronegócio como uso de insumos tradicionais e até transgênicos. A incoerência existente entre as diferentes formas de atuação na atividade da aquicultura pode ser vencida por tomadas de decisões e ajustes metodológicos adaptados as devidas proporções e infraestrutura disponível, os quais julgamos capazes de realizar tais interpretações e concretizar as reproduções físicas, ambientais e sociais bem como as interações que permeiam os agroecossistemas trabalhados.

Por fim, percebe-se a aplicação de ferramentas de extensão em atividades práticas em modelos de educação sob Pedagogia da Alternância 
pautados na linguagem e relação campesina propicia uma forte integração entre os participantes, a observância dos fundamentos teóricos e empíricos assimilados pelos discentes, a adequação dos conceitos a serem trabalhados pelos docentes em sala de aula e a contribuição deixada pelos visitantes aos produtores locais, contribuindo assim à riqueza de saberes.

O curso técnico no âmbito PRONERA instiga aos educandos a clareza sobre a complexidade do mundo rural advinda da trama composta por dimensões sociais, econômicas e ambientais. Além de, profissionalmente, prepará-los para os desafios que os aguardam, na realidade plural que estão imersos, assertivas ratificadas pela maturidade e profusão das discussões pautadas pelos participantes.

\section{REFERÊNCIAS}

ALBANO, Gleydson Pinheiro; SÁ, Alcindo José de. Vale do Açu-RN: a passagem do extrativismo da carnaúba para a monocultura de banana. Revista de Geografia, Recife, v. 26, n. 3, p. 6-32, set/dez. 2009. Disponível em: https://periodicos.ufpe.br/revistas/revistageografia/article/view/228766. Acesso em: 03 set. 2020.

BARROSO, Renata Melon et al. Dimensão socioeconômica da tilapicultura no Brasil. Brasília: Embrapa, 2018. 110p. ISBN 978-85-7035-773-1. Disponível em:

https://www.infoteca.cnptia.embrapa.br/infoteca/bitstream/doc/1089746/1/CN PASA2018Ivdimensao.pdf. Acesso em: 24 jul. 2020.

\section{BRASIL. Programa Nacional de Educação na Reforma Agrária}

(PRONERA): manual de operações. Brasília: MDA, 2016. 145p. Disponível em: https://www.gov.br/incra/pt-br/assuntos/reforma-

agraria/manual_pronera_18.01.16.pdf. Acesso em: 22 jun. 2020.

CABALLERO, Luis et al. Los procesos organizativos de la agricultura familiar y la creación de ferias y mercados de economía social. Otra Economía, São Leopoldo, v. 6, n. 7, p. 26-41, jul. 2010. Disponível em:

http://revistas.unisinos.br/index.php/otraeconomia/article/view/1300. Acesso em: 02 jul. 2020 .

CERNEA, Michael. Riesgos de emprobrecimiento y reconstrucción: un modelo para el desplazamiento y la relocalización de poblaciones. Avá (Revista de Antropología), Posadas, n. 5, p. 1-12. 2004.

CODEVASF - Companhia de Desenvolvimento dos Vales do São Francisco e do Parnaíba. Sistema Itaparica. Disponível em:

https://www.codevasf.gov.br/linhas-de-negocio/irrigacao/sistema-itaparica. Acesso em: 12 ago. 2020. 
CONDEPE/FIDEM - Agência Estadual de Planejamento e Pesquisas de Pernambuco. Anuário Estatístico de Pernambuco 2016: Contas regionais. Disponível em: http://www.anuario.pe.gov.br/categoria/contasregionais/contas-regionais. Acessado em: 24 mar. 2020.

\section{CRUZ, Rogério Pires da. Mercados de terras agrícolas no semiárido}

nordestino: constituição, desenvolvimento e dinâmica recente. 2014. 211 p. Tese (Doutorado em Desenvolvimento Econômico) - Universidade Estadual de Campinas, Instituto de Economia, Campinas, SP. 2014. Disponível em: http://www.repositorio.unicamp.br/handle/REPOSIP/286445. Acesso em: 24 jul. 2020.

FARIA, Regina Helena Sant'Ana de et al. Manual de criação de peixes em viveiro. Brasília: Codevasf, 2013. 136p. ISBN: 978-85-89503-13-6. Disponível em: https://www.codevasf.gov.br/acesso-ainformacao/institucional/biblioteca-geraldo-rocha/publicacoes/publicacoeseditadas-pela-codevasf/manuais/manual-de-criacao-de-peixes-emviveiros_reedicao-2019.pdf. Acesso em: 11 jul. 2020.

FEARNSIDE, Philip M. Belo Monte: Actors and arguments in the struggle over Brazil's most controversial Amazonian dam. Die Erde, v. 148, n. 1, p. 14-26, abr. 2017. Disponível em: https://doi.org/10.12854/erde-148-27. Acessado em: 27/12/2020.

FÉLIX, Nelson Marques. Programa nacional de educação na reforma agrária (PRONERA): história, estrutura, funcionamento e características. Revista Território e Cidadania, Brasília, v.1, n.1, p. 49-61, dez. 2015.

GALVÃO, Olímpio José de Arroxelas. O Projeto de Reassentamento de Itaparica e sua inserção no marco das novas políticas de desenvolvimento regional para o Nordeste. Cadernos de Estudos Sociais, Recife, v. 15, n. 1, p. 33-66, jan. 1999. Disponível em: https://fundaj.emnuvens.com.br/CAD/article/view/1233. Acesso em: 18 jul. 2020.

GARCIA, Sylvia Gemignani. A tecnologia social como alternativa para a reorientação da economia. Estudos Avançados, São Paulo, v. 28, n. 82, 251 275, out. 2014. Disponível em: https://doi.org/10.1590/S010340142014000300015 . Acesso em 21 jul.2020.

GONÇALVES, Alicia Ferreira. Experiências em economia solidária e seus múltiplos sentidos. Revista Katálysis, Florianópolis, v. 11, n. 1, p. 132-142, jan/jun. 2008. Disponível em:

https://periodicos.ufsc.br/index.php/katalysis/article/view/4828. Acesso em: 14 jul. 2020.

GUIMARÃES, Flávia Gabel; VENDRAMINI, Ana Lúcia do Amaral. Gestão do conhecimento da cadeia do pescado. In: ADDOR, Felipe. Extensão e políticas 
públicas: o agir integrado para o desenvolvimento social. Rio de Janeiro: Editora UFRJ, 2015. p. 255-280.

HESS, Christoph Ernst Emil; FENRICH, Eva. Socio-environmental conflicts on hydropower: The São Luiz do Tapajós project in Brazil. Environmental Science \& Policy, v. 73, p. 20-28, jul. 2017. ISSN 1462-9011. Disponível em: https://doi.org/10.1016/j.envsci.2017.03.005. Acessado em: 23/12/2020.

IBGE - Instituto Brasileiro de Geografia e Estatística. Censo agropecuário 2017: resultados definitivos. Rio de Janeiro: IBGE. 2019. Disponível em: https://sidra.ibge.gov.br/pesquisa/censo-agropecuario/censo-agropecuario2017. Acesso em: 21 jul. 2020.

KIYOTA, Norma; PERONDI, Miguel Ângelo; VIEIRA, José Antônio Nunes. Estratégia de sucessão geracional na agricultura familiar: o caso do condomínio Pizzolatto. Informe Gepec, Toledo, v. 16, n. 1, p. 192-211, jan. 2012. Disponível em: http://erevista.unioeste.br/index.php/gepec/article/view/5581. Acesso em: 20 jul. 2020.

KUBITZA, Fernando. Tilápia: tecnologia e planejamento na produção comercial. Jundiaí: F. Kubitza, 2000. 289p.

LIMA, Sérgio Ricardo Ribeiro. Barragem de Itaparica: vinte anos após o programa de reassentamento - (des)envolvimento e (des)estruturação de vidas. In: ENCONTRO CIÊNCIAS SOCIAIS E BARRAGENS, 2., 2007, Salvador. Anais [...]. Salvador: UFBA. 2007. p. 1-26. Disponível em: http://www.ecsb2007.ufba.br/layout/padrao/azul/ecsb2007/anais/st4_BARRA GEM\%20DE\%20ITAPARICA.pdf. Acesso em: 16 jun.2020.

LOPES, Maria Mirian Moreira Sampaio. Os alimentos transgênicos nos limites do princípio da precaução e a Responsabilidade Civil do Estado em eventuais danos ambientais. 2017. 65 f. Monografia (Graduação em Direito) - Faculdade de Ciências Jurídicas e Sociais, Centro Universitário de Brasília, Brasília, 2017. Disponível em:

https://repositorio.uniceub.br/jspui/handle/235/11309. Acesso em: 25 jun. 2020.

MELO, Christiana Sarmento; MIYATA, Marina Hiromi. A aplicação das metodologias da pedagogia da alternância e da análise diagnóstico de sistemas agrários em assentamentos do estado do Ceará. Revista Brasileira de Agroecologia, Dois Vizinhos, v. 4, n. 2, p.1138-1142, nov. 2009. Disponível em: http://revistas.abaagroecologia.org.br/index.php/rbagroecologia/article/view/8155. Acesso em: 13 ago. 2020. 
MENEZES, Luciano Silva de; MARQUES, Juracy; NOVAES, Joaquim Alves. Perfil histórico e sociocultural da "Velha" Petrolândia/PE. In: MARQUES, Juracy; Almeida, Alfredo Wagner Berno de; MENEZES, Luciano Silva de (Org.).

Barrando as Barragens: o início do fim das hidroelétricas. Paulo Afonso: Editora SABEH, 2017. p. 203-216.

NAVARRO, Zander. Desenvolvimento rural no Brasil: os limites do passado e os caminhos do futuro. Estudos Avançados, São Paulo, v. 15, n. 43, p. 83-100, dez. 2001. Disponível em: https://doi.org/10.1590/S010340142001000300009. Acesso em: 29 jul. 2020.

NOBRE, Larissa Emanuely Silva et al. Segurança alimentar: riscos e benefícios da ingestão dos alimentos transgênicos na saúde humana. Diversitas

Journal, Santana do Ipanema, v. 5, n. 1, p.283-297, jan./mar. 2020.

Disponível em:

https://periodicos.ifal.edu.br/diversitas_journal/article/view/1001. Acesso em: 18 jul. 2020.

NOSELLA, Paolo. Educação no campo: origens da pedagogia da alternância no Brasil. Vitória: EDUFES, 2012. 288p.

PEREIRA, Marcos Newton et al. Métodos e meios de comunicação em extensão rural. Porto Alegre: EMATER/RS. 2009. 40p.

PERES, Marcos Augusto de Castro. Um movimento social do semiárido? A Articulação do Semiárido Brasileiro entre a sustentabilidade e a reforma agrária. In: SIMPÓSIO PÓS-ESTRUTURALISMO E TEORIA SOCIAL, 2., 2017, Pelotas. Anais [...]. Pelotas: UFPEL. 2017. p. 1-17. Disponível em: https://wp.ufpel.edu.br/legadolaclau/files/2017/10/Marcos-Peres.pdf. Acesso em: 13 jul. 2020.

PEZZATO, Luiz Edivaldo; BARROS, Margarida Maria; FURUYA, Wilson Massamitu. Valor nutritivo dos alimentos utilizados na formulação de rações para peixes tropicais. Revista Brasileira de Zootecnia, Viçosa, v. 38, n. spe, p. 43-51, jul. 2009. Disponível em: https://doi.org/10.1590/S151635982009001300005. Acesso em: 13 jul. 2020.

RANDELL, Heather. The short-term impacts of development-induced displacement on wealth and subjective well-being in the Brazilian Amazon. World Development, v. 87, p. 385-400, nov. 2016. ISSN 0305-750X. Disponível em: https://doi.org/10.1016/j.worlddev.2016.07.005. Acesso em: 26 dez. 2020.

ROCHA, Bruno Cardoso Gonçalves da; VITAL, Tales. A piscicultura em tanquerede no município de petrolândia - pe: um arranjo produtivo local em construção. Revista em Agronegócios e Meio Ambiente, Maringá, v. 5, n. 3, p. 475-492, set./dez. 2012. Disponível em: 
https://periodicos.unicesumar.edu.br/index.php/rama/article/view/1847. Acesso em: 28 jun. 2020.

SANTOS, Elton Lima et al. Digestibilidade de ingredientes alternativos para tilápia-do-nilo (Oreochromis niloticus): revisão. Revista Brasileira de

Engenharia de Pesca, São Luiz, v. 3, n. 2, p. 135-149, abr. 2008. Disponível em: https://ppg.revistas.uema.br/index.php/REPESCA/article/view/93. Acesso em: 02 jul. 2020.

SARTORI, Alan Giovanini de Oliveira; AMANCIO, Rodrigo Dantas. Pescado: importância nutricional e consumo no Brasil. Segurança Alimentar e Nutricional, Campinas, v. 19, n. 2, p. 83-93, fev. 2012. Disponível em: https://doi.org/10.20396/san.v19i2.8634613. Acesso em: 03 jul. 2020.

SCOTT, Parry. Negociações e resistências persistentes: agricultores e a barragem de Itaparica num contexto de descaso planejado. Recife: Ed.Universitária da UFPE, 2009. 290 p.

SIGAUD, Lygia. Implicações políticas e sociais de grandes projetos hidroelétricos sobre as populações indígenas e camponesas. Estudos Avançados, São Paulo, v. 16, p. 1-16, mar. 1994. Disponível em: https://documentacao.socioambiental.org/documentos/Q4D00087.pdf. Acesso em: 28 jun. 2020.

SILVA, Edilene Daniela; LIMA, Diogo Silva de; FEITOSA, Aparecido Vieira.

Relatório de Aquicultura. 2020. 6 f. Relatório de aula (Técnico em Agropecuária com ênfase em Agroecologia) - Universidade Federal Rural de Pernambuco, Serra Talhada, 2020.

SILVA, Sandro Pereira; NAGEM, F. A. Dimensões Estruturais dos Empreendimentos de Economia Solidária: Uma Análise para os Estados da Bahia e Paraná. Documentos técnico-científicos, v. 43, n. 2, p. 309-326, abr/jun. 2012. Disponível em:

http://repositorio.ipea.gov.br/bitstream/11058/7424/1/td_2271.pdf. Acesso em: 02 jul. 2020.

SILVA, Vonin da Silva e. Uso do efluente da piscicultura na fertirrigação de olerícolas produzidas com base agroecológica. 2019. 95 f. Dissertação (Mestrado em Agroecologia) - Universidade Estadual de Roraima, Boa Vista, 2019. Disponível em: https://uerr.edu.br/ppga/wpcontent/uploads/2019/08/Disserta\%C3\%A7\%C3\%A3o-AgroecologiaUERR_Vonin-Silva_2019.pdf. Acesso em: 05 jul. 2020.

TEIXEIRA, Edival Sebastião; BERNARTT, Maria de Lourdes; TRINDADE, Glademir Alves. Estudos sobre pedagogia da alternância no Brasil: revisão de literatura e perspectivas para a pesquisa. Educação e Pesquisa, São Paulo, v. 34, n. 2, p. 227-242, mai/ago. 2008. Disponível em: 
https://doi.org/10.1590/S1517-97022008000200002. Acesso em: 11 jul. 2020.

WANDERLEY, Maria de Nazareth Baudel. Agricultura familiar e campesinato: rupturas e continuidade. Estudos Sociedade e Agricultura, Rio de Janeiro, v. 21 , p. $42-61$, out. 2003 . Disponível em: https://revistaesa.com/ojs/index.php/esa/article/view/238. Acesso em: 21 set. 2020.

\section{Agradecimentos}

Os autores agradecem a coordenação estadual em Pernambuco do Programa Nacional de Educação na Reforma Agrária - PRONERA, e Universidade Federal Rural de Pernambuco - UFRPE, por contribuir para a execução e elaboração deste trabalho.

Recebido em: 9 de março de 2021.

Aceito em: 8 de abril de 2021. Publicado em: 15 de dezembro de 2021. 